Волжская Булгария: археология, история, культура

УДК 902/904 https://doi.org/10.24852/2587-6112.2021.3.11.18

\title{
К ВОПРОСУ ОБ ИСТОКАХ ФОРМИРОВАНИЯ ГОРОДСКОЙ КУЛЬТУРЫ ВОЛЖСКОЙ БУЛГАРИИ
}

\author{
(C) 2021 г. М. Акынджи
}

В статье исследуются истоки градостроительства волжских болгар. Вопрос тесно связан с процессом оседания кочевых и полукочевых болгар на землю. При исследовании ранних постоянных поселений болгар VIII-X вв. на основе археологических и письменных источников мы видим, что формирование этих поселений происходило на разных территориях их обитания (Хазарский каганат, ранняя Булгария). Истоки градостроительной культуры волжских булгар связаны с эпохой хуннов, Тюркских каганатов и Хазарского каганата. Первые постоянные поселения болгар появляются в VIII-IX вв., а укрепленные поселения городского типа - не позднее рубежа IX-X вв.

Ключевые слова: археология, волжские булгары, городская культура, постоянные поселения, хунны, Тюркский каганат, Хазарский каганат.

\section{THE ISSUE OF THE FORMATION OF URBAN CULTURE IN VOLGA BOLGARIA}

\begin{abstract}
M. Akıncı
The paper addresses the origins of the urbanism of the Volga Bolgars. The issue is closely related to the settlement process of nomadic and semi-nomadic Bolgars. Examining the early stable settlements of the Bolgars in the $8^{\text {th }}-10^{\text {th }}$ centuries based on archaeological and written sources, one can see that these settlements were formed in different regions where they were inhabited (Khazar Khaganate, Early Bolgaria). The origins of the urbanization culture of the Volga Bolgars are connected with the Xiongnu, Turkic and Khazar Khaganate periods. The first stable settlements of the Bolgars emerged in the $8^{\text {th }}-9^{\text {th }}$ centuries, and fortified urban-type settlements - not later than at the turn of the $9^{\text {th }}-10^{\text {th }}$ centuries.

Keywords: archaeology, Volga Bolgars, urban culture, stable settlements, Xiongnu, Turkic Khaganate, Khazar Khaganate.

Понятие «город» неоднозначно применительно к древнейшим городам Ближнего Востока, более поздним мусульманским городам того же региона, а также Средней Азии, Волжской Булгарии или Золотой Орды. Какие условия необходимы для того, чтобы поселение было названо городом? По мнению исследователей, критерии города различаются от периода к периоду, и даже специалисты не всегда проявляют единогласия в определении социального сущности отдельно взятых поселений (Мумфорд, 2007, с. 13). В прошлом древнетюркское слово balik (город) соответствовало слову şehir персидского происхождения, или слову kent (город) согдийского происхождения, которые использовалось в основном после того, как тюрки приняли ислам. Согласно М. Кашгарлы, слово balık означало «убежище, замок, город» на тюркском языке до принятия ислама (Kaşgarli Mahmud, 2015, c. 163).

В самых общих чертах принято считать, что город должен превосходить сельскую местность с точки зрения численности насе-

ления, выполнять ремесленные, торговые и административные функции и, что, наиболее важно, находиться в защищенном положении. Если мы примем эти критерии в качестве общего знаменателя для определения города, то окажется, что некоторые из поселений средневекового Запада, а в основном поселения восточных обществ не следует определять как города. Хотя есть сходства в процессах формирования западных и восточных городов (исламских и неисламских), явные различия преобладают. В этом отношении было бы некорректно описывать средневековые города на основе одного определения или в рамках единой модели.

Территория Татарстана и соседних с ним регионов, где проживали в эпоху средневековья волжские булгары, расположена на перекрестке важнейших речных и караванных путей Восточной Европы и в природногеографическом отношении относится преимущественно к зонам лесостепи и степи с обширными лугами для выпаса скота и черноземными полями для выращивания земледель-
\end{abstract}


ческих культур. По этой причине ВолжскоКамский регион в силу своей географической и климатической пригодности на протяжении тысячелетий являлся одним из густо заселенных регионов Восточной Европы.

Постоянные поселения с примитивными жилищами возникли здесь еще в каменном веке; намного позже, в эпоху раннего средневековья с приходом кочевых орд с востока, появились не только кочевья с переносными юртами и стационарными жилищами, но и крепости и настоящие города, что мы наблюдаем в Хазарском каганате. В целом же, как нам представляется, в процессе возникновения стационарных поселений, ведущих к формированию болгарских городов и городской культуры, сыграли ведущую роль три основных фактора: культура поселений волжско-камских аборигенов - финно-угров эпохи камня, бронзы и раннего железа, культура степных поселений тюркских кочевников и культура поселений Хазарского каганата, археологически представленного салтовомаяцкой культурой.

Формирование постоянных поселений в Волжско-Камском регионе началось еще в эпоху мезолита и более интенсивно продолжалось в эпоху неолита - энеолита (IV - начало II тыс. до н.э.), когда складывались такие формы производящего хозяйства, как земледелие и животноводство, получившее дальнейшее распространение и развитие в первобытных обществах бронзового века (II - начало I тыс. до н.э.) (Халиков, 1969; Габяшев, 2001). На территории Татарстана к настоящему времени выявлено более 300 неолитических поселений, расположенных в основном на долинах Волги и Камы. При их раскопках выявлены остатки жилищ-полуземлянок прямоугольной формы площадью от 60-70 до $100-120$ кв. м.

Эпоха бронзы в Татарстане представлена памятниками балановской, срубной, абашевской, черкаскульской культур и памятниками маклашеевского (позднеприказанского) типа. Они оставлены населением, говоряшим, по предположению ученых, на европейских, иранских и финно-угорских языках. Поселения балановцев располагаются на высоких естественно укрепленных мысах, иногда огражденных земляными валами и рвами. Жили они в срубных домах площадью около 16-24 кв. м. Срубняки расселялись не только по долинам крупных рек, но и осваивали земли по их притокам. Площадь поселений а их количество около 500 только в Татарста- не! - обычно не превышает 10 тыс. кв. м; на них изучены срубные дома в виде полуземлянок (Казаков, 2001, с. 56-66).

Ананьинские поселения раннего железного века (VIII-III вв. до н.э.) занимают, как правило, высокие берега рек. Для городищ выбирали треугольные мысы, ограниченные глубокими оврагами или крутым берегом реки, а не защищенную естественной преградой сторону укрепляли искусственным валом и рвом. При раскопках поселений археологи выявляют вытянутые прямоугольные или квадратной формы наземные, иногда слегка углубленные в землю жилища (Марков, 2001, с. 76-77).

Ананьинская традиция строительства городищ и жилищ продолжалась и в пьяноборское время (II в. до н.э. - III в. н.э.). На основе вышеуказанных культур сложились основы средневековых культур финно-угорских народов края, тесно контактировавших позднее с пришедшими с юга болгарами. Как отмечают археологи, финно-угорские элементы заметны в домостроительстве и фортификационном деле волжских булгар (Хузин, 2001, с. 268; Губайдуллин, 2019, с. 155).

Одной из интересных и во многом еще загадочных археологических культур раннего средневековья является именьковская культура, сложившаяся в Среднем Поволжье в IV веке и существовавшая практически до конца VII в., когда сюда проникла первая волна переселившихся с юга болгар. Первые памятники именьковцев (а их сейчас известно более 600 ), а именно Именьковское городище и Рождественский могильник с кремациями, были изучены еще в 50-х годах прошлого века и с этого времени не затухают споры об этнической принадлежности населения, оставившего эти памятники. Раньше большинство исследователей относили именьковцев к числу тюркоязычных племен, в последние годы преобладает точка зрения об их славянском происхождении. Дискуссия об этносе именьковцев прямо не касается нашей темы. Отметим лишь, что с этим пришлым населением связано распространение в крае пашенного земледелия с применением тягловой силы лошадей, установление активных контактов с соседними финно-угорскими и славянским племенами, народами Средней Азии.

Поселения именьковской культуры располагаются группами, которые включают в себя городище (иногда два) и пять-шесть селищ. Городища обычно занимают мысы коренных террас рек. Зафиксированы факты использования именьковцами пустующих городищ 
населения раннего железного века. Форма их площадок подтреугольная, подчетырехугольная, трапециевидная, овальная. Преобладают мысовые городища подтреугольной формы. Размеры площадей колеблются от 0,5 тыс. до 20 тыс. кв. м. Большими размерами выделяется Большетарханское городище, занимающее площадь около 560 тыс. кв. м. Уязвимая сторона поселений окружена земляным валом и рвом, иногда двойным или даже тройным валом и рвом. Земляные укрепления дополнялись деревянными бревенчатыми стенами, поставленными по гребню вала (Старостин, 2001, с.100-101. На некоторых городищах и всех исследованных сельских поселениях обнаружены остатки жилищ - землянки и полуземлянки с очагами типа чувалов, а также хозяйственные сооружения, предназначенные для хранения продуктов и рабочего инвентаря. Выявлены также остатки гончарных и металлургических горнов, производственных мастерских (Казаков и др., 1987, с. 32).

Именьковцы - это непосредственные предшественники болгар на Средней Волге и Нижнем Прикамье. Хотя они, как полагают, были изгнаны с насиженных мест на свои прежние земли, часть их, скорее всего, оставалась здесь же и смешалась с новыми пришельцами - болгарами. Естественно полагать, что болгары, недавние кочевники, начавшие оседать на землю, многое переняли от них и местных финно-угров в области хозяйственной жизни, домо- и градостроительства. В этом смысле не лишена логики высказанная еще в 1950-е годы и отвергнутая теперь теория A.М. Ефимовой о происхождении булгарских городов на основе укрепленных поселений предшествующего позднегородецкого или именьковского, как принято сейчас называть, населения (Ефимова, 1957).

Теперь рассмотрим роль степных народов в сложении градостроительной культуры волжских булгар.

Небольшие группы тюркских племен поселились в Поволжье задолго до булгар. Как известно, в I в. н.э. расположенное в Центральной Азии государство гуннов распалось из-за внутренних конфликтов, и часть из них вынуждена была мигрировать на запад. Следует подчеркнуть, что гунны вели полукочевой образ жизни и у них были города, один из которых, Иволгинское городище в Забайкалье, было основательно изучено в свое время археологами (Давыдова , 1985; Кызласов, 2006, с. 142 и сл.). Оно представляло собой мощную крепость подквадратной формы размерами 34×340 м общей площадью около 11, 5 га. Кстати, подквадратными были все хорошо сохранившиеся гуннские города в соседней Монголии. Стены Иволгинского городища состояли из четырех укрепленных линий, от которых сохранились валы и рвы с двумя въездными воротами. Сооружались эти укрепления следующим образом: сначала по всему периметру строящейся крепости были выкопаны три рва глубиной до 2-5 м и шириной 3,5 - 5,5 м, затем перед ними сооружались «галькобетонные» стенки. Они воздвигались путем заливки в деревянные опалубки слоев глины и песка с добавлением речной гальки. Получалось сцементированное тело стены высотой до 2 м. На этих стенах (валов) сооружали деревянные заборы (Кызласов, 2006, с. 151-152).

Выявлена квартальная застройка внутреннего пространства городища. Внутри кварталов находились усадьбы из двух-трех жилых домов, а также хозяйственные и производственные сооружения: зернохранилища, погреба, колодцы, остатки гончарных и металлургических мастерских.

B II-IV вв. н.э. происходила миграция хуннов с востока на запад, в степи Восточной Европы (Гумилев, 2003, с. 303), но она, кажется, не внесла существенных изменений в этнополитическую карту региона, хотя исследователи находят истоки фортификации булгарских городов именно в культуре хуннских городов (Губайдуллин, 2019, с. 155-156).

Более существенным представляется вклад в формирование культуры волжских булгар населения Тюркских каганатов. Как и свои предшественники хунны, древние тюрки представляли собой общество, экономика которого базировалась на кочевом способе скотоводческого хозяйства в степях, хлебопашестве, ремесле, торговле в районах с оседлым населением. Город и степь были частями единого социально-экономического организма, дополняющими друг друга. Города являлись, прежде всего, административными центрами, а те из них, которые располагались на границе между кочевыми и оседлыми районами, становились центрами торговли (Кызласов, 2006, с. 219 и сл.).

Хазары занимают важное место в истории средневековой тюрко-татарской цивилизации. Из этого государственного образования вышли тюркоязычные болгары, савиры, барсилы, беленджеры, которые, покинув по разным причинам свою прежнюю родину, поднимались на Среднюю Волгу и состави- 
ли основное ядро формирующегося Булгарского государства (Хузин, 2006, с. 37-40). Они принесли с собой и некоторые достижения своей прежней культуры, в том числе и навыки, приобретённые в строительстве и ремесле. Волжско-булгарские города по своей топографической структуре, строительным приёмам напоминают города Хазарии, возникшие в VII-VIII веках в приморской зоне современного Дагестана, на Дону и в Нижнем Поволжье.

Столичный город Итиль, располагавшийся в дельте Волги между двумя её рукавами, состоял из трёх частей: его кварталы располагались на обоих берегах Волги, а на самой реке был остров с резиденцией кагана, окружённой высокой кирпичной стеной. Вокруг дворца располагались богатые дома аристократии и обычные жилища рядовых горожан, занятых в основном обслуживанием верхушки общества. В других частях Итиля обитали преимущественно ремесленники и торговцы. Как сообщают источники, один из районов города принадлежала мусульманам, количество которых доходило до 10 тысяч (История татар, 2006, с. 747).

В Хазарии продолжалось массовое оседание кочевников на землю. Археологами выявлены следы неукреплённых поселений, городища с земляными валами, замки с остатками каменных стен, города-крепости. На этих памятниках открыты полуземлянки и стационарные юртообразные жилища. Наиболее плодородные земли и торговые пути в центральной части каганата контролировались системой белокаменных городов-крепостей. Знаменитая крепость Саркел на Нижнем Дону, построенная византийскими мастерами, имела прямоугольную форму $(180 \times 120$ м), стены сложены из обожжённого кирпича квадратной формы, без фундамента. На кирпичах сохранились знаки мастеров, которые мы также видим на строительных камнях дунайских болгар (Ögel, 2014, c. 231). Крепость разделена на две части «цитадель» для размещения военного отряда и «караван-сарай», где останавливались иноземные купцы. Стены дополнительно укреплены башнями, в том числе и угловыми. У главных ворот вырыт глубокий колодец, круглый в плане, стенки которого были облицованы отёсанным камнем. С внешней стороны юго-западной стены располагались железоплавильные и гончарные горны, дома-полуземлянки, хозяйственные постройки и ямы (Артамонов, 1958, с. 7 и сл.).
Среди крепостей выделяется также археологический комплекс у с. Маяки и Семикаракорская крепость на Дону (Флеров, 2011). К Маяцкому городищу, расположенному на высоком холме, примыкали неукреплённые селища. Наиболее крупным из них является поселение у с. Сидорово на правом берегу Северского Донца. Территория его густо застроена жилыми и хозяйственными постройками. Жители строили как наземные дома, так и полуземлянки. Отопительные сооружения разнообразны: очаги, расположенные в центре помещения, печи-каменки, печи глинобитные и даже тандыры. Такое разнообразие свидетельствует о пёстром этническом составе жителей (Плетнева, 1984, c. 14-19).

Высокие достижения хазар в области материальной и духовной культуры, хозяйственной жизни и градостроительства, были приумножены их наследниками в лице волжских булгар.

Культуру населения Хазарского каганата, сохранившуюся в памятниках салтово-маяцкой археологической культуры, преемственно продолжают болгары на Волге, о чем наглядно свидетельствуют как погребальный обряд ранних могильников типа Больших Тархан, так и инвентарь языческих погребений (Генинг, Халиков, 1964; Плетнева, 1963, с. 240).

О времени возникновения первых постоянных поселений переселившихся с юга болгар существуют разные мнения (Греков, 1945, с. 23; Казаков, 1982, с. 33; Казаков, 1999, с. 98 ; Хузин (Хузин, 2001, с. 58-59; Руденко, 2012, c. 71). Арабские писатели свидетельствуют об оседлости у болгар в начале X в. Например, Ибн Русте, писавший свою работу между 903-913 годами, упоминал, что в булгарских селениях есть мечети и школы, и они занимаются земледелием и торговлей (Хузин, 2006, c. 210-211). Ал-Балхи также подчеркивает оседлый образ жизни булгар, но замечает, что они предпочитают жить летом в юртах, а зимой в бревенчатых домах (Хвольсон, 1869, с. 82). Сведения письменных источников находят подтверждение в материалах археологии. Комплекс погребений новинковского типа в Самарско-Ульяновской области, связанный с первым движением болгар на Среднюю Волгу, показывает, что болгарские кочевники занимались земледелием еще первой половине VIII в. (Матвеева, 1997, с. 99).

Помимо сельскохозяйственных навыков болгарских племен, прибывающих в регион, их знакомство с местной земледельческой 
культурой способствовало формированию стабильных поселений. Ю.А. Семыкин в Ульяновской области исследовал поселение Абрамовское VIII в. и обнаружил, что материалы раннеболгарского периода (керамические изделия, железные ножи, пряжки конской сбруи и др.) имеют прямое сходство с коллекцией находок из большетарханских погребений. При металлографическом анализе изделий из железа также выявлена технология, характерная для кузнечного комплекса большетарханского населения. По мнению исследователя, комплекс средневекового Абрамовского поселения представляет собой сезонные поселения ранних болгар на стадии перехода к оседлости (Семыкин, 1996, с. 68-69, 74-78).

Хазарские кочевники в VIII-IX веках привезли новые культурные элементы салтово-маяцкой оседлой культуры Юго-Восточной Европы (гончарного дела, металлургии, домостроительства) в Поволжье, способствовавшие возникновению стационарных поселений сельского типа и а позднее и настоящих городов (Надырова, 2012, с. 31-32).
Таким образом, постоянные поселения, которые явились первым этапом в процессе зарождения городов Волжской Булгарии, имели разные истоки происхождения. Оседлая культура, населявшаяся вокруг Волги и Камы еще до нашей эры и возглавляемая финно-уграми, является первым примером таких постоянных поселений. Миграция тюркоязычных народов с востока на запад привела к появлению степной культуры, основанной на кочевом образе жизни. Булгары, которые были наследниками салтово-маяцкой археологической культуры, сформировавшейся на территории Хазарского каганата в VII в., также были вовлечены в этот процесс, где взаимодействие оседлых и кочевых культур ярко проявилось в градостроительстве и типах жилищ (переносные и стационарные юрты, землянки и полуземлянки). Можно утверждать, что булгарские поселения на Средней Волге образовались под влиянием или на основе постоянных поселений предшествующих культур.

\section{ЛИТЕРАТУРА}

Артамонов М.И. Саркел - Белая Вежа // МИА. № 62 / Отв. ред. М.И. Артамонов. М.-Л.: АН СССР, 1958. C. $7-84$.

Археологические памятники Центрального Закамья / Отв. ред. А.Х. Халиков. Казань: ИЯЛИ КФАН CCCP, 1988. $98 \mathrm{c}$.

Габящев Р. Нижнее Прикамье в эпоху неолита // Очерки по археологии Татарстана / Ред. П.Н. Старостин и др. Казань: Изд-во «Школа», 2001. С. 34-43.

Генинг В.Ф., Халиков А.Х. Ранние болгары на Волге (Больше-Тарханский могильник). М.: Наука, 1964. $200 \mathrm{c}$.

Греков Б.Д. Волжские болгары в IX-X вв. // Исторические записки. Т. XIV. / Отв. ред. Б. Д. Греков М.: Изд-во АН СССР, 1945. С. 3-37.

Губайдуллин А.M. Фортификация в Среднем Поволжье в X- первой половине XVI вв. / Археология Евразийских степей. 2019. № 3, 323 с.

Давыдова А.В. Иволгинский комплекс (городище и могильник) - памятник хунну в Забайкалье. Л.: ЛГУ, 1985. $111 \mathrm{c.}$

Ефимова A.M. К вопросу о происхождении городов Волжской Болгарии. Казань: Госмузей ТАССР, 1957. $18 \mathrm{c}$.

История татар с древнейших времен в семи томах. Т. II. Волжская Булгария и Великая степь / Отв. ред. Ф.Ш. Хузин. Казань: РухИЛ, 2006. 960 с.

Казаков Е.П. Об археологическом изучении раннеболгарского периода // Новое в археологии и этнографии Татарии / Отв. ред. А.Х. Халиков. Казань: ИЯЛИ КФАН, 1982. С. 29-37.

Казаков Е.П. Некоторые итоги и задачи изучения древностей Волжской Болгарии // Научное наследие А. П. Смирнова и современные проблемы археологии Волго-Камья. Тезис. науч. конф. М., 1999. С. 96-99.

Казаков Е.П. Памятники эпохи бронзы // Очерки по археологии Татарстана / Отв. ред. П.Н. Старостин. Казань: Школа, 2001. С. 56-73.

Казаков Е.П., Старостин П.Н., Халиков А.Х. Археологические памятники Татарской АССР. Казань: Татар. кн. изд-во, 1987. 240 с.

Красильников К. И. Возникновение оседлости у праболгар Среднедонечья // СА. 1981. № 4. С. 110-125.

Кызласов Л.Р. Городская цивилизация Срединной и Северной Азии: исторические и археологические исследования. М.: Вост. лит., 2006. 360 с. 
Марков В.Н. Общая характеристика раннего железного века. Памятники Нижнего Прикамья VIII-V вв. // Очерки по археологии Татарстана / Отв. ред. П.Н. Старостин. Казань: Школа, 2001. C. $74-83$.

Матвеева Г.И. Могильники ранних болгар на Самарской Луке. Самара: Самарский университет, 1997. $226 \mathrm{c}$. $291 \mathrm{c}$.

Надырова Х.Г. Градостроительная культура Татарского народа и его предков. Казань: КГАСУ, 2012.

Плетнева С.А. Кочевнический могильник близ Саркела-Белой вежи // МИА. № 109. М.: Наука,1963. C. 216-259.

Плетнева С.А. Маяцкое городище // Маяцкое городище / Отв.ред. С.А. Плетнева. М.: Наука, 1984. C. 3-19.

Руденко К. А. Возникновение городов в Волжской Булгарии и Булгарской области Золотой Орды (поданным археологии) // Поволжская археология. 2012. №1. С. 68-77.

Семыєкин Ю.А. К вопросу о поселениях ранних Болгар на Самарской Луке // Культуры Евразийских степей второй половины I тысячелетия н. э. / Отв. ред. Д.А. Сташенков. Самара: Самарский областной историко-краеведческий музей им. П.В. Алабина, 1996. С. 66-82.

Смирнов А.П. Волжские булгары / Труды ГИМ. Вып. ХІХ. М.: ГИМ, 1951. 275 с.

Старостин П. Н. Именьковская культура // Очерки по археологии Татарстана / Ред. П. Н. Старостин. Казань, 2001. С. 100-118.

Флеров В.С. Три проблемы в истории Хазарского каганата // Салтово-маяцька археологічна культура: 110 років від початку вивчення на Харківщині: збірник наукових праць, присвячений проблемам та перспективам салтовознавства, за матеріалами Міжнарод. наук. конф. «П'ятнадцяті слобожанські читання» / упоряд. Г.С. Свистун. Харьков: Видалець Савчук О.О., 2011. С. 97-104.

Халиков А.Х. Древняя история Среднего Поволжья. М.: Наука, 1969. 394 с.

Халиков А. Х. К вопросу о начале тюркизации населения Поволжья и Приуралья // СЭ. 1972. № 1. C. $110-118$.

Халиков А.Х. Татарский народ и его предки. Казань: Татар. кн. изд-во, 1989. 221 с.

Халиков А.X. Основы этногенеза народов Среднего Поволжья и Приуралья. Часть І. Происхождение финноязычных народов (Учебное пособие). Казань: изд-во Казан. ун-та, 1991. 108 с.

Халиков Н. Сельское хозяйство. Промыслы // История татар с древнейших времен (в семи томах). Том II. Волжская Булгария и Великая Степь / Отв. ред. Ф.Ш. Хузин. Казань: РухИЛ, 2006. С. 236-239.

Хвольсон Д.А. Известия о хозарах, буртасах, болгарах, мадьярах, славянах и руссах Абу-Али Ахмеда бен Омар Ибн-Даста, неизвестного доселе арабского писателя начала X века, по рукописи Британского музея. СПб.: Тип. Импер. акад. наук, 1869. 199 с.

Хузин Ф.Ш. Болгарский город в начале Х-ХІІІ вв. Казань: Мастер Лайн, 2001. 480 с.

Хузин Ф.Ш. Ранние булгары и Волжская Булгария (VIII - начало XIII вв.). Казань, 2006. 583 с.

Artamonov M.I. Hazar Tarihi. İstanbul: Selenge, 2008. 670 s. 736.

Mumford L. Tarih Boyunca Kent: Kökenleri, Geçirdiği Değişimler ve Geleceği. İstanbul: Ayrıntı Yayınları,

Ögel B. İslamiyetten Önce Türk Kültür Tarihi. Ankara, 2014. 455 s.

Şeşen R. İslam Coğrafyacılarına Göre Türkler ve Türk Ülkeleri. Ankara: TTK Basımevi, 2001. 300 s.

Gumilev L. N. Hunlar. İstanbul: Selenge, 2003. $665 \mathrm{~s}$.

Kaşgarlı Mahmud. Dîvanû lügâti't-Türk, Giriş-Metin-Çeviri-Notlar-Dizin. Haz. A. Ercilasun ve Z. Akkoyunlu. Ankara: TDK, 2015. $995 \mathrm{~s}$.

Taşağll A. Göktürkler I-II-III. Ankara: TTK, 2018. 473 s.

\section{Информация об авторе:}

Акынджи Мелтем, докторант, Университет Акдениз (г. Анталия, Турция); mltm.akinci@hotmail. com.

\section{REFERENCES}

Artamonov, M. I. 1958. In Artamonov, M. I. (ed.). Materialy i issledovaniia po arkheologii SSSR (Materials and Research in the USSR Archaeology) 62. Moscow; Leningrad: the USSR Academy of Sciences, 7-84 (in Russian). 
Khalikov, A. Kh (ed.). 1988. Arkheologicheskie pamiatniki Tsentral'nogo Zakam'ia (Archaeological Monuments of the Central Trans-Kama Region). Kazan: Institute of Language, Literature and History, Kazan Branch of the USSR Academy of Sciences (in Russian).

Gabiashev, R. S. 2001. In Starostin, P. N. (ed.). Ocherki po arkheologii Tatarstana: Uchebnoe posobie dlia studentov vuzov i uchitelei istorii (Essays on the Archaeology of Tatarstan: Textbook for University Students and Teachers of History). Kazan: "Shkola" Publ., 34-43 (in Russian).

Gening, V. F., Khalikov, A. Kh. 1964. Rannie bolgary na Volge (Bol'she-Tarkhanskii mogil'nik) (Early Bolgars on the Volga River (Bolshie-Tarkhany Burial Ground)). Moscow: "Nauka" Publ. (in Russian).

Grekov, B. D. 1945. In Grekov, B. D. (ed.). Istoricheskie zapiski (Historical Notes) 14. Moscow: USSR Academy of Sciences, 3-37. (in Russian).

Gubaidullin, A. M. 2019. Fortifikatsiia v Srednem Povolzh'e v X-pervoi polovine XVI vv. (Fortification in the Middle Volga Region in the $10^{\text {th }}$ - first half of the $16^{\text {th }}$ Centuries) In Arkheologiia evraziiskikh stepei (Archaeology of the Eurasian Steppes). 3. (in Russian).

Davydova, A. V. 1985. Ivolginskiy kompleks (gorodishhe i mogil'nik) - pamyatnik khunnu v Zabaykal'e (Ivolginsky Complex (Fortified Settlement and Burial Ground) - a Monument to the Xiongnu in Transbaikalia). Leningrad: Leningrad State University (in Russian).

Efimova, A. M. 1957. K voprosu o proiskhozhdenii gorodov Volzhskoy Bolgarii (The Issue of the origin of Volga Bolgar Cities). Kazan: State Museum of the Tatar ASSR (in Russia).

Khuzin, F. Sh. (ed.). 2006. Istoriia tatar s drevneishikh vremen $v$ semi tomakh (History of the Tatars since Ancient Times in seven volumes. 2. Kazan: "Rukhil" Publ. (in Russian).

Kazakov, E. P. 1982. In Khalikov, A. Kh. (ed.). Novoe v arkheologii $i$ etnografii Tatarii (Recent in the archaeology and ethnography of Tataria). Kazan: G. Ibragimov Language, Literature and History Institute, Kazan Branch of the USSR Academy of Sciences, 29-37 (in Russian).

Kazakov, E. P. 1999. In Nauchnoe nasledie A. P. Smirnova i sovremennye problemy arkheologii VolgoKam'ia (A. P. Smirnov's Scientific Legacy and Modern Issues of Volga-Kama Archaeology). Moscow, 96-99 (in Russian).

Kazakov E.P. 2001. In Starostin, P. N. (ed.). Ocherki po arkheologii Tatarstana: Uchebnoe posobie dlia studentov vuzov i uchitelei istorii (Essays on the Archaeology of Tatarstan: Textbook for University Students and Teachers of History). Kazan: "Shkola" Publ., 56-73 (in Russian).

Kazakov, E. P., Starostin, P. N., Khalikov, A. Kh. 1987. Arkheologicheskie pamiatniki Tatarskoi ASSR (Archaeological Sites of the Tatar ASSR). Kazan: “Tatarskoe knizhnoe izdatel'stvo" Publ. (in Russian).

Krasilnikov, K. I. 1981. In Sovetskaia Arkheologiia (Soviet Archaeology) (4), 110-125 (in Russian).

Kyzlasov, L. R. 2006. Gorodskaia tsivilizatsiia Sredinnoi i Severnoi Azii: istoricheskie i arkheologicheskie issledovaniia (Urban Civilization of Central and Northern Asia: Historical and Archaeological Studies). Moscow: "Vostochnaia literatura" Publ. (in Russian).

Markov, V. N. 2001. In Starostin, P. N. (ed.). Ocherki po arkheologii Tatarstana: Uchebnoe posobie dlia studentov vuzov i uchitelei istorii (Essays on the Archaeology of Tatarstan: Textbook for University Students and Teachers of History). Kazan: "Shkola" Publ., 74-83 (in Russian).

Matveeva, G. I. 1997. Mogil'nik rannikh bulgar na Samarskoi Luke (Burial grounds of the early Bulgars on the Samara Luka). Samara: Samara State University (in Russian).

Nadirova, Kh. G. 2012. Gradostroitel'naia kul tura Tatarskogo naroda i ego predkov (Urban Culture of the Tatar People and their Ancestors). Kazan: Kazan State University of Architecture and Endineering (in Russia).

Pletneva, S. A. 1963. Materialy i issledovaniia po arkheologii (Proceedings and Research in Archaeology of the USSR) 109. Moscow: "Nauka" Publ., 216-259 (in Russian).

Pletneva, S. A. 1984. In Pletneva, S. A. (ed.). Maiatskoe gorodishche (Mayaki Fortified Settlement). Moscow: "Nauka" Publ., 3-19 (in Russia).

Rudenko, K .A. 2012. In Povolzhskaia arkheologiia (Volga River Region Archaeology) (1), 68-77. (in Russian).

Semykin, Yu. A. 1996. In Stashenkov, D. A. (ed.). Kul'tury evraziiskikh stepei vtoroi poloviny I tysiacheletiia n.e. (voprosy khronologii) (Cultures of the Eurasian Steppes in the Second Half of I Millennium AD (Issues of Chronology).). Samara: Samara Regional Museum of Local Lore named after P. V. Alabin, 66-82 (in Russian).

Smirnov, A. P. 1951. Volzhskie bulgary (Volga Bulgars). Series: Trudy Gosudarstvennogo istoricheskogo muzeia (Proceedings of the State Historical Museum). XIX. Moscow: State Historical Museum (in Russian). 
Starostin, P. N. 2001. In Starostin, P. N. (ed.). Ocherki po arkheologii Tatarstana: Uchebnoe posobie dlia studentov vuzov i uchitelei istorii (Essays on the Archaeology of Tatarstan: Textbook for University Students and Teachers of History). Kazan: "Shkola" Publ., 100-118 (in Russian).

Flerov, V. S. 2011. In Svistun, G. E. (ed.-in-chief). Saltovo-maiac'ka arkheologichna kul'tura: 110 rokiv vid pochatku vivchennia na Kharkivshchini (The Saltovo-Mayaki Archaeolgical Culture: 110the Anniversary of the Study in Kharkiv Region). Kharkiv: Publisher Savchuk O.O., 97-104 (in Russian).

Khalikov, A. Kh. 1969. Drevniaia istoriia Srednego Povolzh'ia (Ancient History of the Middle Volga Region). Moscow: "Nauka" Publ. (in Russian).

Khalikov, A. Kh. 1972. In Sovetskaia etnografiia (Soviet Ethnography) (4), 110-118 (in Russian).

Khalikov, A. Kh. 1989. In Tatarskii narod $i$ ego predki (The Tatar People and Their Ancestors). Kazan:"Tatarskoe knizhnoe izdatel'stvo" Publ. (in Russian).

Khalikov, A. Kh. 1991. Osnovy etnogeneza narodov Srednego Povolzh'ia i Priural'ia. Chast' I. Proiskhozhdenie finnoiazychnykh narodov (Uchebnoe posobie) (Fundamentals of the Ethnic Genesis of Middle Volga and Cis-Ural Peoples). Kazan: Kazan State University (in Russian).

Khalikov, N. A. 2006. In Khuzin, F. Sh. (ed.). Istoriia tatar s drevneishikh vremen v semi tomakh (History of the Tatars since Ancient Times in seven volumes. 2. Kazan: "RukhIL" Publ., 236-239 (in Russian).

Khvol'son, D. A. 1869. Izvestiia o Khazarakh, Burtasakh, Bolgarakh, Mad'iarakh, Slavianakh i Russakh Abu Ali Akhmeda Ben Omar Ibn-Dasta, neizvestnogo dosele arabskogo pisatelia nachala X veka, po rukopisi Britanskogo muzeia (News of the Khazar, Burtas, Bulgar, Magyar, Slavs and Russ by Abu Ali Ahmed ben Omar ibn Dasta, Hitherto Unknown Arabic Writer of the Beginning of the $10^{\text {th }}$ Century, the Manuscript of the British Museum for the First Time Published). Saint Petersburg: Typography of the Imperial Academy of Sciences (in Russian).

Khuzin, F. Sh. 2001. Bolgarskii gorod v nachale X-XIII vv. (Bolgar City at the Beginning of the $10^{\text {th }}-13^{\text {th }}$ $c c$.$) . Kazan: "Master Lain" Publ. (in Russian).$

Khuzin, F. Sh. 2006. Rannie bulgary i Volzhskaia Bulgariia (VIII - nachalo XIII v.) (Early Bulgars and Volga Bulgaria ( $8^{\text {th }}-$ Early $13^{\text {th }}$ Centuries)). Kazan: "Foliant" Publ. (in Russian).

Artamanov, M. I. 2008. Hazar Tarihi (History of Khazar.) İstanbul: Selenge Yayınları (in Turkish).

Mumford, L. 2007. Tarih Boyunca Kent: Kökenleri, Geçirdiği Değişimler ve Geleceği (City Throughout History). İstanbul: Ayrıntı Yayınları (in Turkish).

Ögel B. 2014. İslamiyet'ten Önce Türk Kültür Tarihi. (Turkic Cultural History Before Islam). Ankara (in Turkish).

Şeşen R. 2001. İslam Coğrafyacılarına Göre Türkler ve Türk Ülkeleri. (Turks and Turkish Countries According to Islamic Geographers). Ankara: TTK Basımevi (in Turkish).

Gumilev L.N. 2003. Hunlar. (Khuns) İstanbul: Selenge (in Turkish).

Kaşgarli Mahmud. 2015. Divanu Lügati t-Türk, Giriş-Metin-Çeviri-Notlar-Dizin (Divanu Lugati t-Turk, Introduction-Text-Translation-Notes-Index). Haz. A. Ercilasun ve Z. Akkoyunlu. Ankara: TDK (in Turkish).

Taşağıl, A. 2018. Göktürkler I-II-III. (Gokhturks I-II-III). Ankara: TTK Yayınları (in Turkish).

\section{About the Author:}

Meltem Akıncl. Ph.D(c), Akdeniz University, Institute of Social Sciences, Department of History. Dumlupınar Boulevard 07058 Campus, Antalya, Turkey; mltm.akinci@hotmail.com

Статья поступила в журнал 01.04.2021 г. Статья принята к публикации 01.04.2021 г. 